Article

\title{
Large-Area Fabrication of Structurally Colored and Humidity Sensitive Composite Nanofilm via Ultrasonic Spray-Coating
}

\author{
Sijun Li, Donghui Kou, Shufen Zhang and Wei Ma *
}

check for updates

Citation: Li, S.; Kou, D.; Zhang, S.; Ma, W. Large-Area Fabrication of Structurally Colored and Humidity Sensitive Composite Nanofilm via Ultrasonic Spray-Coating. Polymers 2021, 13, 3768. https://doi.org/ $10.3390 /$ polym 13213768

Academic Editor: Ho-Hsiu Chou

Received: 29 September 2021

Accepted: 26 October 2021

Published: 30 October 2021

Publisher's Note: MDPI stays neutra with regard to jurisdictional claims in published maps and institutional affiliations.

Copyright: (c) 2021 by the authors. Licensee MDPI, Basel, Switzerland. This article is an open access article distributed under the terms and conditions of the Creative Commons Attribution (CC BY) license (https:// creativecommons.org/licenses/by/ $4.0 /)$.
State Key Laboratory of Fine Chemicals, Dalian University of Technology, No.2 Linggong Road, Gaoxinyuan District, Dalian 116023, China; lisijunok@mail.dlut.edu.cn (S.L.); koudonghui1993@mail.dlut.edu.cn (D.K.); zhangshf@dlut.edu.cn (S.Z.)

* Correspondence: weima@dlut.edu.cn; Tel.: +86-411-84986265

\begin{abstract}
Intelligent structural colors have received extensive attention in recent years due to their diverse applications. However, the large-area, uniform, and cost-effective fabrication of ultra-thin structural color films is still challenging. Here, for the first time, we design and employ an ultrasonic spray-coating technique with non-toxic, green nano-silica and polyvinylpyrrolidone as raw materials, to prepare structural color films on silicon wafers. Due to the addition of polyvinylpyrrolidone, the coffee-ring effect during droplet drying is suppressed and uniform composite films are formed. We further perform a detailed study of the influence of various processing parameters including silica/polyvinylpyrrolidone concentration, substrate temperature, nozzle-to-substrate distance, and number of spray-passes on film roughness and thickness. By increasing the number of spray-passes from 10 to 30, the film thickness from 120 to $340 \mathrm{~nm}$ is modulated, resulting in different colors, and large-area and uniform colors on commercial round silicon wafers with $15 \mathrm{~cm}$ diameter are achieved. The silica/polyvinylpyrrolidone composite films show strong hydrophilicity and are sensitive to humidity changes, leading to quickly tunable and reversible structural colors. Quartz crystal microbalance with dissipation demonstrates water vapor adsorption and condensation on the nanofilm when increasing environmental humidity. Thereby, ultrasonic spray-coating as a novel film fabrication technique provides a feasible scheme for large-area preparation of intelligent structural colors.
\end{abstract}

Keywords: composite structural color films; ultrasonic spray-coating; large-area; hydrophilic property; humidity sensitive

\section{Introduction}

Replacing chemical colors with artificial structural colors has attracted more and more attention due to contamination from chemical dyes and pigments, and easy fading of chemical colors [1,2]. Structure color, which arises from the physical interaction of visible light with micro- and nano-fabricated ordered structures, has a lot of advantages, such as having good light stability, and being pollution-free and fadeless [3,4]. However, the superior advantage that chemical colors can be manufactured on an industrial scale makes it difficult to find substitutes for them $[5,6]$. There are still enormous challenges to replace chemical colors with artificial structural ones [7].

Attention has been paid to thin-film interference due to its use of a simple structure to achieve color control through the adjustment of layer thickness and refractive index $[8,9]$. The phenomenon occurs when the incident light wave is reflected off each boundary of the membrane and the two reflected waves interfere with each other to form a new wave. When the membrane is uniform and its thickness is comparable with the wavelength of visible light, structural colors are produced [10].

In nature, some animals are colored by the principle of film interference, showing a variety of attractive colors. Some squids can produce iridescent colors, which are caused by the light reflection of platelet stacks and can be adjusted with the thickness change of the platelets [11]. Moreover, living organisms can change their colors for communication 
and camouflage by tuning the thickness or volume of their protein soft layer or cell [12]. For example, the longhorn beetle changes the color of its elytron from green to red when the environmental humidity increases due to water vapor adsorption [13]. Inspired by the intelligent colors in nature, artificial colors have been constructed for diverse applications $[14,15]$. Previously, the reported ultra-thin films have mainly been assembled via spinor dip-coating, or fabricated utilizing atomic layer deposition (ALD) or sputter deposition techniques [16-18]. However, these methods have limitations in scale-up and economical preparation. Thus, large-scale and low-cost fabrication of structurally colored smart nanofilm is highly desirable and remains challenging.

Spray-coating is an alternative and promising way to realize the large-scale objective because of its advantages of economical nature, convenience, practicability, and ease of scaling up to large production volumes [19]. However, traditional spray-coating with air pressure for atomization cannot achieve accurate control of layer thickness in the nanoscale due to larger droplet sizes [20]. In recent years, another novel technique (ultrasonic spraycoating) has developed quickly. With this technique, high-frequency ultrasonic vibration produces a fine mist of solution with droplets of $10-30 \mu \mathrm{m}$ in size, which is beneficial for precise control of film thickness [21-24]. Although this method shows many advantages, achieving a uniform thin layer with structural colors is still challenging and has not previously been reported. During the spray process, the formed droplets are deposited on a substrate where they coalesce to form a coating [25]. However, when a droplet containing nonvolatile solutes dries on a solid surface, it leaves a dense, ring-like deposit along the perimeter, forming a "coffee ring" on the surface, which greatly affects the uniformity and color of the film [26,27].

A drop of evaporating water is a difficult-to-control, complex, non-equilibrium system [28]. Except for capillary flow, the evaporating droplet features a gas-liquid interface shaped like a spherical cap and Marangoni flows caused by surface tension gradients between the top of the droplet and the contact line [29]. Attempts to ameliorate or reverse the coffee-ring effect have focused on manipulating capillary flows and Marangoni flows [30]. Liying Cui et al. reported that adding water-soluble polymers to microsphere dispersion could effectively suppress the coffee-ring effect [31]. The polymer additives cause contact line motion due to their viscosity and the Marangoni effect, which results in a reduced amount of solutes depositing on the edge of the droplet. In addition, depositions from water drops containing nanoparticles and different concentrations of sodium dodecyl sulfate have been investigated [32]. As the droplets evaporate, the concentration of the surfactants increases locally, generating strong gradients in the surface tension to generate Marangoni flows, which can prevent most solutes from reaching the contact line, leading to a more uniform deposition of nanofilm.

Herein, for the first time, we use the ultrasonic spray-coating technique, with nanosilica and polyvinylpyrrolidone (PVP) to fabricate large-area tunable structure colors on silicon wafers. $\mathrm{SiO}_{2}$ is a widely used inorganic film-forming material, and it shows the properties of non-toxicity, good stability, and hydrophilicity [33,34]. PVP is a kind of biocompatible nonionic polymer; it can assist in dispersing nanoparticles and adjust the viscosity of the system [35]. The incorporation of $\mathrm{PVP}$ in $\mathrm{SiO}_{2}$ dispersion will benefit the formation of the homogeneous film. The processing scheme for nanofilm preparation and schematic of PVP adsorption on the surface of silica particles are presented in Figure 1a. This shows that under the action of a carrier gas, small droplets are formed through the ultrasonic nozzle, which is sprayed onto the substrate; through repeated cycles, a film with a certain thickness is achieved. The nozzle generates a fine mist of droplets by highfrequency vibration, as shown in Figure 1b. The color is generated by the interference of the two reflected light waves from the air-nanofilm, and film-silicon substrate interfaces (Figure 1c). In this study, droplet drying processes were monitored under a microscope, and a comparison was made between $\mathrm{SiO}_{2}$ and $\mathrm{SiO}_{2} / \mathrm{PVP}$ droplets. Processing parameters were optimized to achieve low surface roughness. Through adjusting the number of spray passes, tunable structural color films with different sizes were achieved. In addition, it was 
found that the as-prepared films showed strong hydrophilicity and were very sensitive to humidity changes, demonstrating their excellent visual sensing functionality.

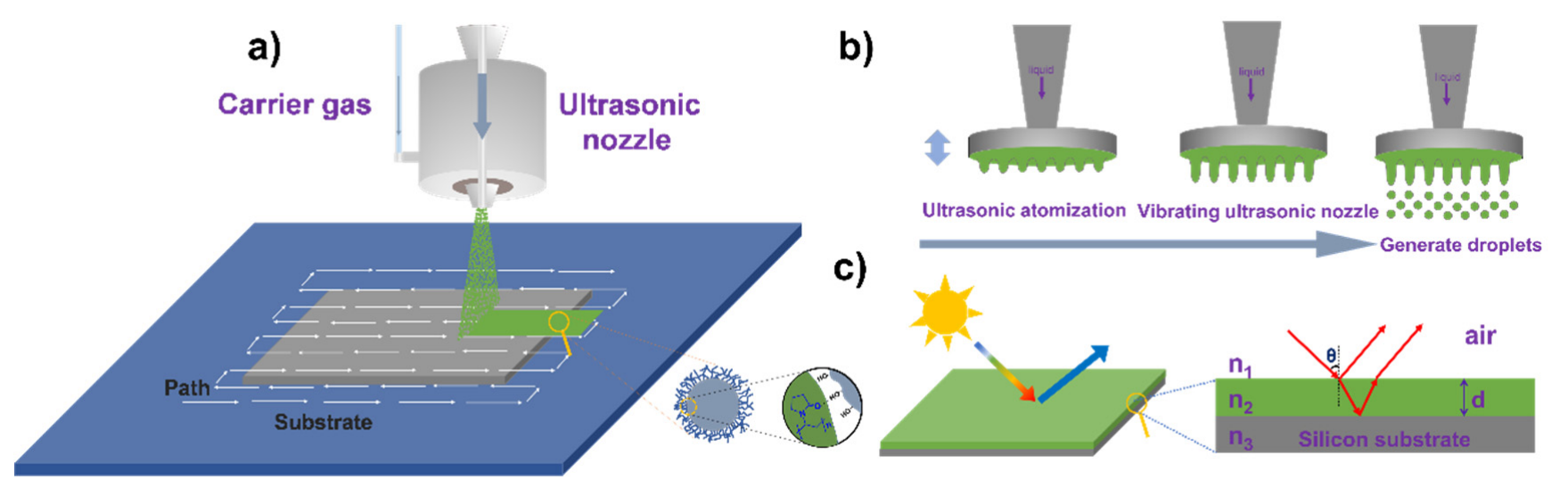

Figure 1. (a) Preparation scheme of structural color film with ultrasonic spray-coating technique, and schematic of PVP adsorption on the surface of silica particles. (b) The process of ultrasonic nozzle producing droplets. (c) Schematic of interference of the two reflected light waves from the air-film and film-silicon substrate. $n_{1}, n_{2}, n_{3}$ are the refractive indices of air, $\mathrm{SiO}_{2}$, and silicon substrate, respectively. $\mathrm{d}$ is the thickness of the $\mathrm{SiO}_{2}$ /PVP film. $\theta$ is the incident angle.

\section{Materials and Methods}

\subsection{Materials}

The nano-silica $\left(\mathrm{SiO}_{2}\right)(30.0 \mathrm{wt} \%$, Aladdin, Shanghai, China), Polyvinylpyrrolidone (PVP) average molecular weight $5.5 \times 10^{4}$ (Shanghai Qiangshun Chemical Reagent, Shanghai, China). Round silicon wafers (100) with double-sided polishing and a diameter of $15 \mathrm{~cm}$ (Lijing Silicon Material, Hangzhou, China), were cut into small squares with a size of $2.0 \mathrm{~cm} \times 2.0 \mathrm{~cm}$, and then treated with plasma to be hydrophilic.

\subsection{Preparation of Spray Solution}

$\mathrm{SiO}_{2}$ sol was first obtained by dispersing $\mathrm{SiO}_{2}(30 \mathrm{wt} \%)$ into a certain amount of deionized water and then uniformly dispersing via ultrasonic treatment. In the dispersion, the mass concentrations of $\mathrm{SiO}_{2}$ and PVP were $0.05 \mathrm{wt} \%$ and $0.01 \mathrm{wt} \%$, respectively. We simplified the solution as $\mathrm{SiO}_{2} / \mathrm{PVP}(0.05 / 0.01)$.

\subsection{Process Parameter Optimization of Spraying Equipment}

Spray coating was performed on a UC340 ultrasonic spraying machine (Dongfang Jinrong, Beijing, China) equipped with a D12 ultrasonic nozzle. The main components are illustrated in Figure 1a. The spraying solution was placed in a syringe pump connected by tubing to the atomizing nozzle. The pump was programmed to a constant liquid infusion rate of $0.1 \mathrm{~mL} / \mathrm{min}$. The tip of the ultrasonic atomizer nozzle was actuated at a frequency of $120 \mathrm{kHz}$ with a generator power of $1.5 \mathrm{~W}$. The movement of the nozzle was controlled by an $x-y-z$ stage, and the nozzle path as shown in Figure 1 . The distance between the two nozzle paths was kept at $2 \mathrm{~mm}$, which is smaller than the width of the spray ( 4 mm). The substrate to be coated was placed on the hot plate, and the temperature was varied according to the experimental design. Three values of each variable were selected with the concentration of the spraying solution $\left(\mathrm{SiO}_{2} / \mathrm{PVP}\right)(0.05 / 0.01,0.1 / 0.02,0.15 / 0.03$, and $0.2 / 0.04)$, the substrate temperature $\left(40,50\right.$, and $\left.60^{\circ} \mathrm{C}\right)$, and the distance between the nozzle and substrate $(55,60,65$, and $70 \mathrm{~mm})$ for the spraying experiment on the silicon wafer with a size of $2.0 \mathrm{~cm} \times 2.0 \mathrm{~cm}$. Spraying experiments with optimized parameters were carried out on a round silicon wafer with $15 \mathrm{~cm}$ in diameter.

\subsection{Humidity Response}

Humidity response tests were performed in a sealed container with a digital temperaturehumidity recorder. Different amounts of water was added to the sealed chamber of the sample 
to be tested and converted into water vapor with different relative humidity. The reflectance spectra were recorded after the maximum reflection wavelength was kept constant and the photographs of the samples were captured by a camera (Nikon). All tests were performed at room temperature.

\subsection{Characterization}

Particle hydrodynamic size, distribution, and zeta potential of $\mathrm{SiO}_{2}$ nanoparticles were measured with a particle size analyzer (Zetasizer nano series Nano-ZS100, Malvern, London, UK). The thickness and roughness of the film were measured by an NV5000 profilometer (Zygo Company, Middletown, Connecticut, USA). The cross-section and surface analysis of the films were measured by scanning electron microscopy (SEM, SU8220, Hitachi, Tokyo, Japan). An optical microscope (Autor optics MIT series metallographic microscope) was used to monitor the process of droplet drying. The reflectance spectra of the structural color film at an incident angle of $5^{\circ}$ were measured by a spectrophotometer (U-4100, Hitachi, Tokyo, Japan) and vertically using a fiber-optic spectrometer (PG 2000, Ideaoptics, Shanghai, China). The refractive indexes of the $\mathrm{SiO}_{2}$ layer were measured by an Ellipsometer type Ellip-ER-III under a certain wavelength $(632.8 \mathrm{~nm})$. The structured color film was taken with a camera (Nikon) at $5^{\circ}$ for digital photos. The water contact angles were measured by using a contact-angle system (JC2000D1, Powereach, Shanghai, China). Surface morphology was measured by using an atomic force microscope (Dimension Icon, Bruker, Madison, WI, USA). Mass and viscoelastic change of the $\mathrm{SiO}_{2}$ film were monitored by a quartz crystal microbalance with dissipation (QCM-D, E1 model, Biolin Scientific, Gothenburg, Sweden).

\section{Results}

\subsection{Influence of PVP on Assembly of the Nanofilm}

The properties of $\mathrm{SiO}_{2}$ dispersions without and with PVP were first compared. Figure 2a shows that the average particle size and PDI of the $\mathrm{SiO}_{2}$ are $39.09 \mathrm{~nm}$ and 0.197, respectively, and its zeta potential is $-32.1 \mathrm{mV}$. SiO 2 dispersion in Figure $2 \mathrm{a}$ is transparent and presents good stability at room temperature. In addition, the surface tension of $\mathrm{SiO}_{2}$ dispersion is $71.7 \mathrm{mN} / \mathrm{m}$ (Table S1, Supplementary Material) and its contact angle on a silicon wafer is $35^{\circ}$ (Figure $2 \mathrm{c}$ ). As displayed in Figure $2 b$, the average particle size and PDI of $\mathrm{SiO}_{2} / \mathrm{PVP}$ are $40.26 \mathrm{~nm}$ and 0.262 , respectively, and its zeta potential is $-35.4 \mathrm{mV}$. The surface tension of $\mathrm{SiO}_{2} / \mathrm{PVP}$ dispersion is $68.8 \mathrm{mN} / \mathrm{m}$ (Table S1) and its contact angle on a silicon wafer is $28^{\circ}$ (Figure $2 \mathrm{~d}$ ). This shows that the addition of PVP does not affect much the particle size and surface charge, and $\mathrm{SiO}_{2}$ /PVP is still stable and transparent. Besides, the viscosities of the dispersions at different temperatures were measured as shown in Figure S1. This presents the addition of PVP; the viscosity of the solution increases at all temperatures, which is attributed to the larger viscosity of the polymeric PVP.

The coffee-ring phenomenon produced after droplet drying has an essential influence on the uniformity of the nanofilm, so the droplet drying process was studied and monitored. During the drying process, there are three main flow patterns of nanoparticles in evaporated droplets [36]. The first flow pattern is the transport of particles normally toward the substrate, occurring in the case of gravity, as shown in Figure 3a. The second relevant flow pattern is the radial flow caused by the maximum evaporation rate at the pinned wetting line as shown in Figure $3 \mathrm{~b}$. The third flow pattern is a Marangoni flow presented in Figure 3c. We used $\mathrm{SiO}_{2}(0.05)$ and $\mathrm{SiO}_{2} / \mathrm{PVP}(0.05 / 0.01)$ as spraying solutions, and the sprayed droplets were placed under an optical microscope for observing the drying process. The drying process of $\mathrm{SiO}_{2}$ droplets is shown in Figure $3 \mathrm{~d}$ and Video $\mathrm{S} 1$. The droplets spread out in circles of about $60 \mu \mathrm{m}$ in diameter on the silicon wafer and took $3.6 \mathrm{~s}$ to dry. After drying, the surface left a ring of sediment, producing a distinct coffee-ring phenomenon. 

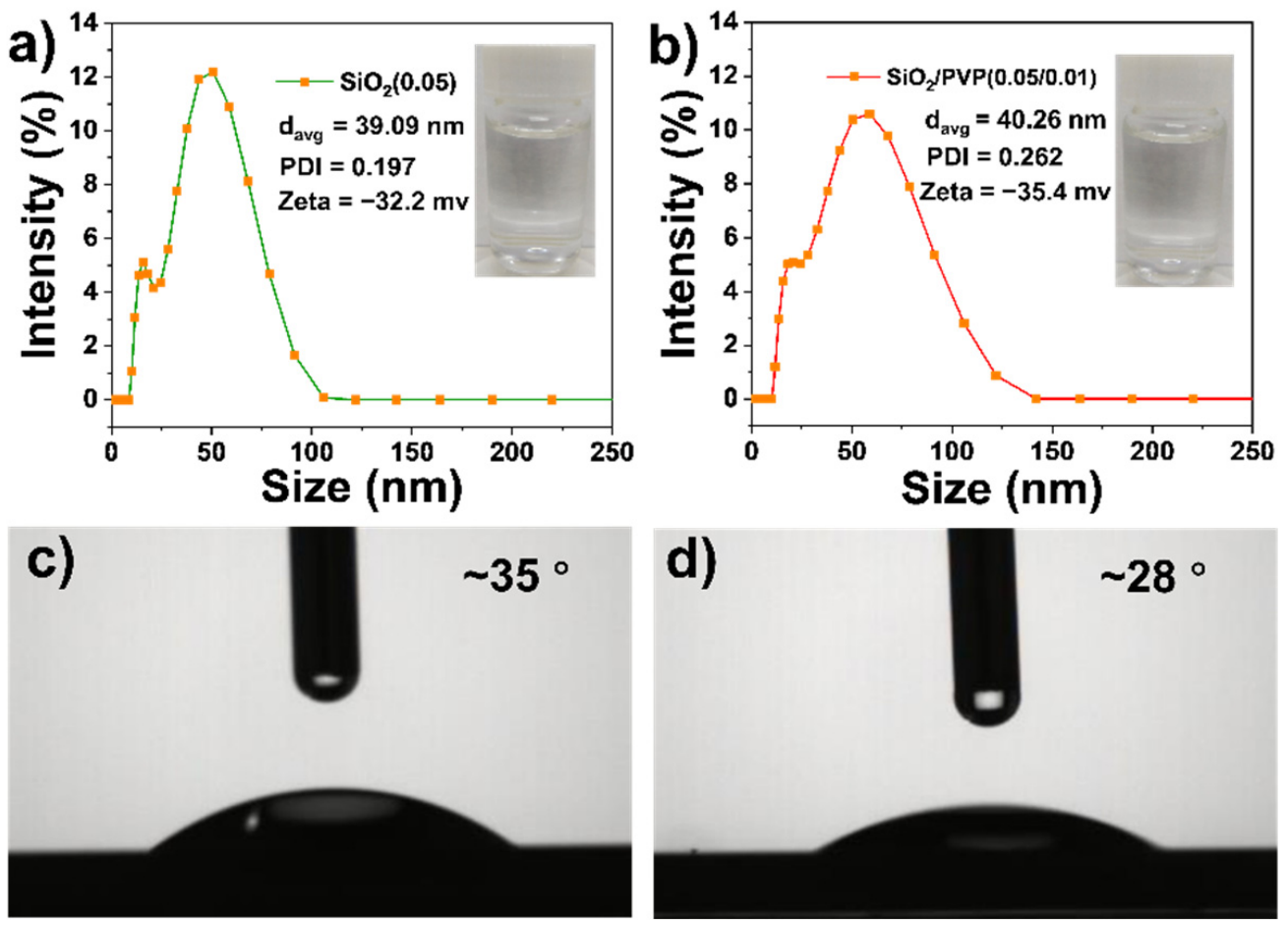

Figure 2. Particle size distribution of (a) $\mathrm{SiO}_{2}(0.05)$ and (b) $\mathrm{SiO}_{2} / \mathrm{PVP}(0.05 / 0.01)$ dispersions in water; contact angles of (c) $\mathrm{SiO}_{2}(0.05)$ and (d) $\mathrm{SiO}_{2} / \mathrm{PVP}(0.05 / 0.01)$ on silicon wafers.

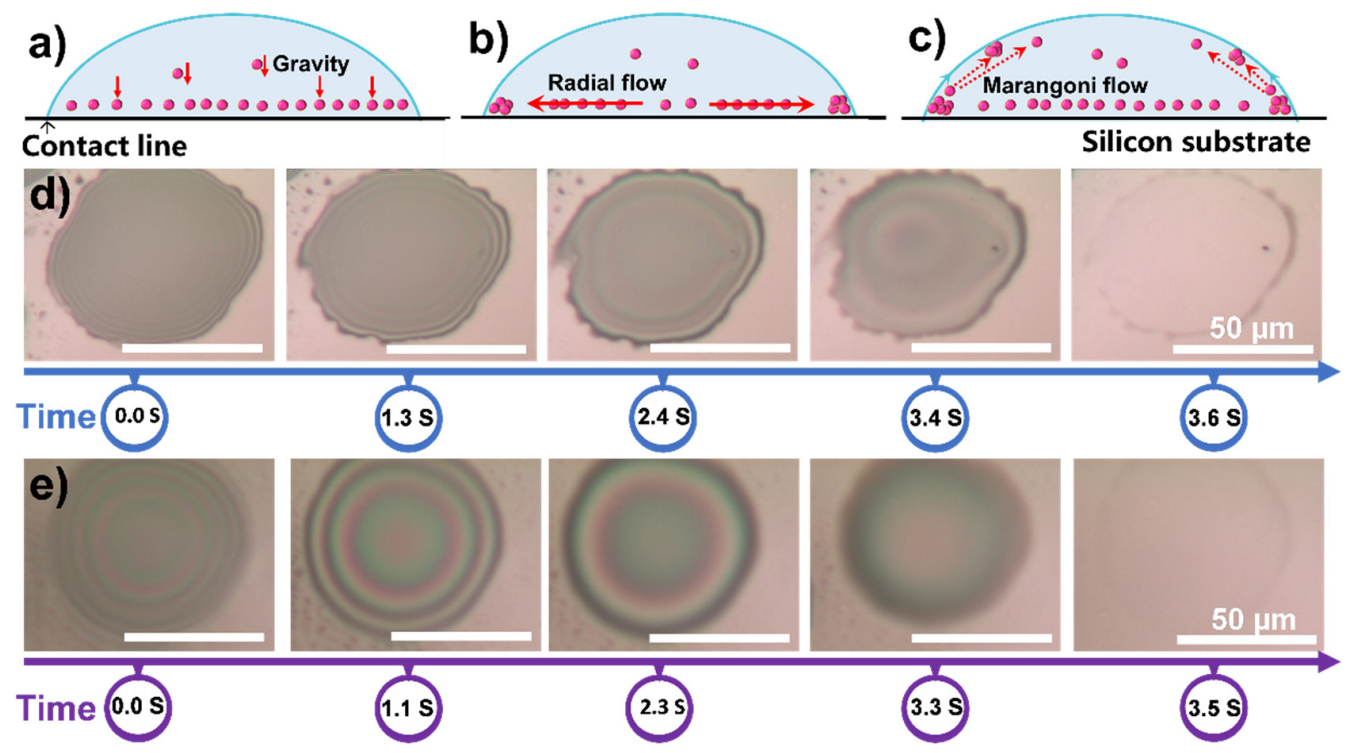

Figure 3. Three main flow patterns of nanoparticles in evaporated droplets of (a) downward flow caused by gravity, (b) radial flow caused by a maximum evaporation rate at the pinned wetting line and (c) Marangoni flow induced by surface tension differences between gas and the liquid interface. Optical microscope images of droplet drying process of (d) $\mathrm{SiO}_{2}(0.05)$ and (e) $\mathrm{SiO}_{2} / \mathrm{PVP}(0.05 / 0.01)$ at different times.

For $\mathrm{SiO}_{2}$ / PVP dispersion, the diffusion area of droplets is also about $60 \mu \mathrm{m}$ and the drying time is $3.5 \mathrm{~s}$, as shown in Figure 3e and Video S2. After drying, the coffee ring on the edge turned out to be unobvious. As can be seen from the dynamic change of the optical image in Figure $3 e$ and the video of the drying process, the fluidity of the solution is enhanced, and the liquid at the edge of the droplet flows gradually to the center, reducing the droplet aggregation at the edge. As a kind of polymer surfactant, and addition of PVP 
can decrease the surface tension of the droplets (see Table S1) and form a difference in surface tension between the droplet edge and the center during the drying process. This promotes Marangoni flow, which is the dispersion at the edge of the droplet flows to the center. In addition, the increased viscosity due to the addition of PVP also resists radial flow of the solute from the center to the droplet edge. Therefore, the promoted Marangoni flow and increased viscosity weaken the coffee-ring effect and are beneficial for forming a uniform film.

We used $\mathrm{SiO}_{2}$ and $\mathrm{SiO}_{2} / \mathrm{PVP}$ as spraying solutions to conduct spraying experiments with spray passes of 10 . By spraying $\mathrm{SiO}_{2}$, we can see a rough surface from its SEM image in Figure $4 \mathrm{a}$. The profilometer scan shows that the surface morphology is rough as presented in Figure 4c. $\operatorname{Ra}\left(R a=\sum_{n=1}^{N}\left|Z_{n}-\bar{Z}\right| / N, Z_{n}\right.$ is the individual height value of the measuring point, and $\bar{Z}$ is the average value of all height points) is $38.1 \mathrm{~nm}$ [37]. As shown in Figure $4 \mathrm{~b}$, the SEM image of $\mathrm{SiO}_{2}$ / PVP film with 10 spray passes shows a uniform surface and the coffee-ring phenomenon is suppressed. The profilometer scan also demonstrates that the $\mathrm{SiO}_{2}$ / PVP surface is homogenous and the obtained $\mathrm{Ra}$ is $10.5 \mathrm{~nm}$, as shown in Figure $4 \mathrm{~d}$. Taking the above spraying results into consideration, the $\mathrm{SiO}_{2}$ and $\mathrm{PVP}$ composite was further used as the spraying solution.
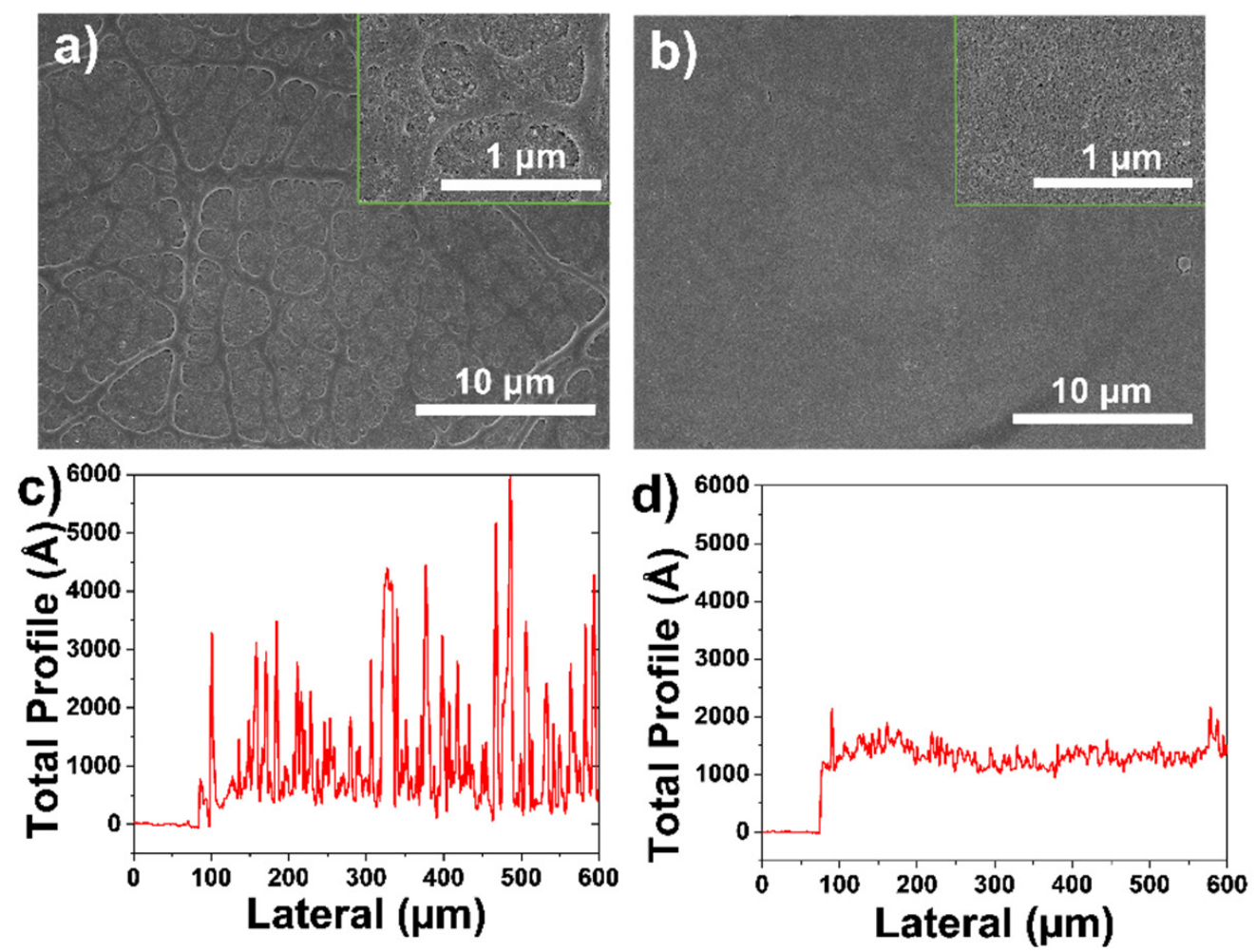

Figure 4. SEM images of film sprayed with (a) $\mathrm{SiO}_{2}$ (0.05) and (b) $\mathrm{SiO}_{2} / \mathrm{PVP}(0.05 / 0.01)$; film surface profiles of spraying solution of (c) $\mathrm{SiO}_{2}(0.05)$ and (d) $\mathrm{SiO}_{2} / \mathrm{PVP}(0.05 / 0.01)$.

\subsection{Process Parameter Optimization of Ultrasonic Spraying Coating}

The uniformity of a film by ultrasonic spray-coating is also influenced by process parameters that need to be regulated to assemble a uniform film [38]. In this work, we performed a detailed study of the influence of the concentration of the solution, the temperature of the substrate $(\mathrm{T})$, the nozzle-substrate distance $(\mathrm{H})$, and the number of spray passes $(\mathrm{N})$ on $\mathrm{Ra}$ and thickness of the spray coating.

Figure 5a and Figure S2 show the results of $\mathrm{Ra}$ and thickness when $\mathrm{SiO}_{2} / \mathrm{PVP}$ concentrations are $0.05 / 0.01,0.10 / 0.02,0.15 / 0.03$, and $0.20 / 0.04 \mathrm{wt} \% / \mathrm{wt} \%$, respectively; $\mathrm{T}$ is $50{ }^{\circ} \mathrm{C}$ and $\mathrm{H}$ is $60 \mathrm{~mm}$. It can be seen that at a close film thickness of about $340 \mathrm{~nm}$, the 
solution concentration has a distinct influence on the layer roughness. When the $\mathrm{SiO}_{2} / \mathrm{PVP}$ concentration is $0.05 / 0.01 \mathrm{wt} \% / \mathrm{wt} \%$, Ra is $24.1 \mathrm{~nm}$; when we further increase the concentration to $0.10 / 0.02,0.15 / 0.03$, and $0.20 / 0.04 \mathrm{wt} \% / \mathrm{wt} \%$, Ra increases to $33.4,45.8$, and $48.7 \mathrm{~nm}$, respectively, indicating that the film becomes rougher. The reason for this result is that the higher the solution concentration, the higher the solute content in the small droplet, and the stronger the coffee-ring effect that will be produced in the drying process.
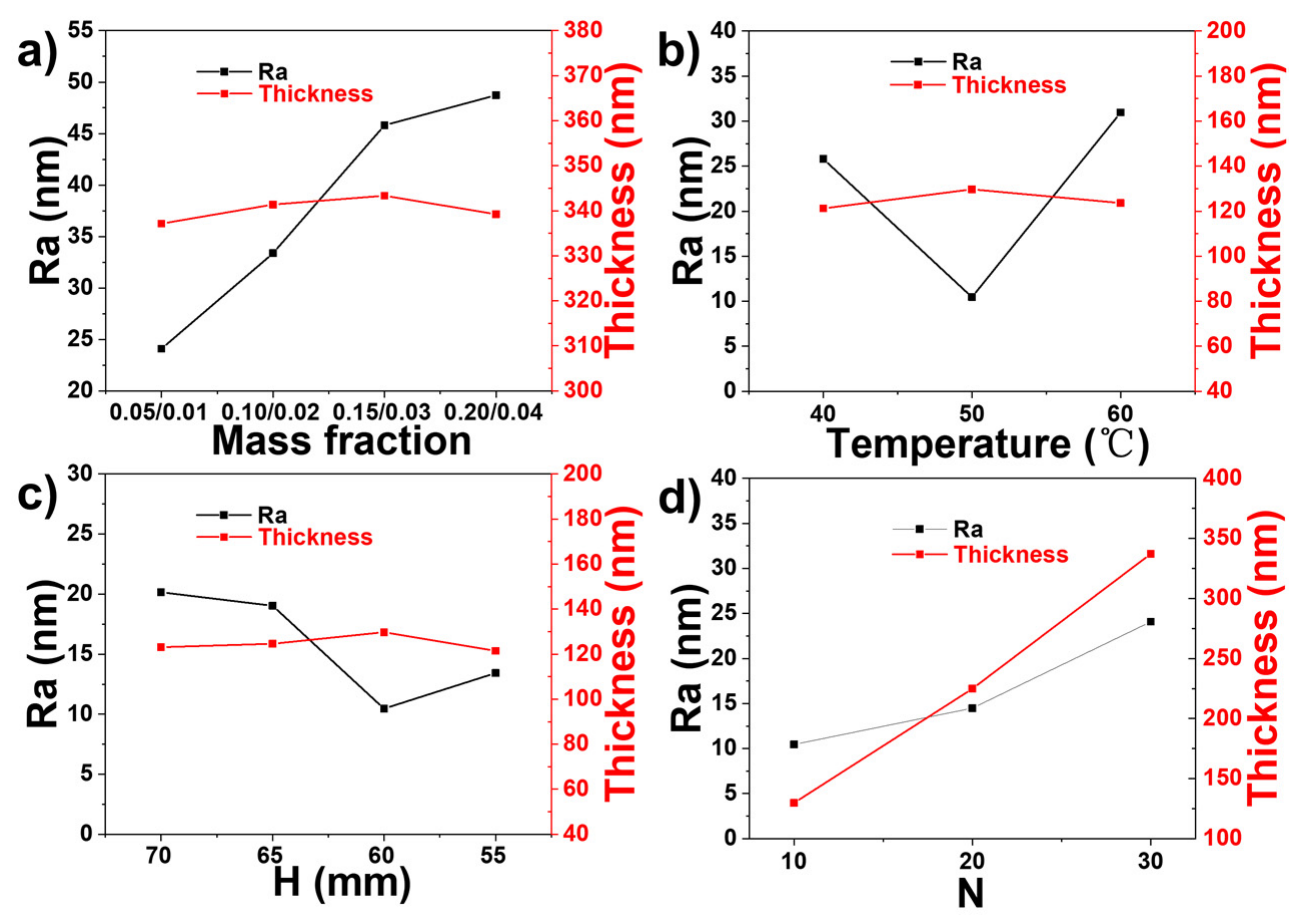

Figure 5. Ra and thickness of $\mathrm{SiO}_{2} / \mathrm{PVP}$ film with (a) solution concentrations of $0.05 / 0.01,0.1 / 0.02$, $0.15 / 0.03$, and $0.2 / 0.04\left(\mathrm{~T}=50^{\circ} \mathrm{C}\right.$ and $\left.\mathrm{H}=60 \mathrm{~mm}\right) ;(\mathrm{b})$ temperature of $=40{ }^{\circ} \mathrm{C}, 50{ }^{\circ} \mathrm{C}$, and $60{ }^{\circ} \mathrm{C}$ (concentration of $0.05 / 0.01$ and $\mathrm{H}=60 \mathrm{~mm}$ ); (c) nozzle-to-substrate distance of 70, 65, 60, and $55 \mathrm{~mm}$ (concentration of $0.05 / 0.01$ and $\mathrm{T}=50^{\circ} \mathrm{C}$ ); $(\mathbf{d})$ number of spraying passes of 10,20 , and 30 (concentration of $0.05 / 0.01, \mathrm{~T}=50^{\circ} \mathrm{C}$, and $\mathrm{H}=60 \mathrm{~mm}$ ).

In Figure $5 \mathrm{~b}$ and Figure S3, keeping the concentration of $\mathrm{SiO}_{2} / \mathrm{PVP}$ at $0.05 / 0.01 \mathrm{wt} \% / \mathrm{wt} \%$, $\mathrm{H}=60 \mathrm{~mm}$ and the number of spray passes $(\mathrm{N})$ of 10 , the substrate temperature increases from $40{ }^{\circ} \mathrm{C}$ to $50^{\circ} \mathrm{C}$, then to $60^{\circ} \mathrm{C}$. This shows that when the temperature is $40{ }^{\circ} \mathrm{C}$, the average layer thickness is $121.2 \mathrm{~nm}$ and $\mathrm{Ra}$ is $25.8 \mathrm{~nm}$; when the temperature is $50{ }^{\circ} \mathrm{C}$, the thickness is $129.7 \mathrm{~nm}$ and roughness decreases to $10.5 \mathrm{~nm}$; and when the temperature increases to $60^{\circ} \mathrm{C}$, thickness and Ra change to $123.6 \mathrm{~nm}$ and $30.9 \mathrm{~nm}$, respectively. It can be observed that with the increase in the substrate temperature, the thickness of the film does not change significantly, while the roughness reaches a minimum value at $50^{\circ} \mathrm{C}$. In the early stages of evaporation, some nanoparticles move outward but do not deposit at the edge. These nanoparticles flow back to the droplet center at the edge of the droplet and form a circular collection of nanoparticles near the gas-liquid interface. However, with the increase in temperature to $50{ }^{\circ} \mathrm{C}$, the Marangoni flow was strengthened, and the flow of the solution at the edge of the droplet was strengthened to the center, so a more uniform deposition was formed after drying. However, when the temperature further rised to $60^{\circ} \mathrm{C}$, it was found Ra was increased, which was mainly due to that higher temperature accelerated the volatilization of water, leading to less even distribution of the solute and increased surface roughness.

Figure $5 \mathrm{c}$ and Figure $\mathrm{S} 4$ give the effect of nozzle-to-substrate distance on the changes in surface roughness. $\mathrm{SiO}_{2} / \mathrm{PVP}(0.05 / 0.01)$ was also used, the substrate temperature was kept at $50^{\circ} \mathrm{C}$, and the investigated distances between the nozzle and the substrate were $70,65,60$, and $55 \mathrm{~mm}$. The results are that $\mathrm{Ra}$ is $20.2,19.1,10.5$, and $13.4 \mathrm{~nm}$, and the film thickness is $123.1,124.6,129.7$, and $121.5 \mathrm{~nm}$, respectively. The minimum Ra value of 
$10.46 \mathrm{~nm}$ was achieved at the height of $60 \mathrm{~mm}$. With the decrease in the distance between the spray nozzle and the substrate, the force of the droplet impacting the substrate becomes larger, and the droplets are well spread on the substrate, weakening the coffee-ring effect. However, when the nozzle-substrate distance drops to $55 \mathrm{~mm}$, the impacting force further increases, and the droplet slides and springs on the substrate during spraying, which affects the uniformity of the surface.

Figure 5d and Figure S5 show Ra and thickness scanned by profilometer at the number of spray passes of 10, 20, and 30. The other conditions used are $\mathrm{SiO}_{2} / \mathrm{PVP}$

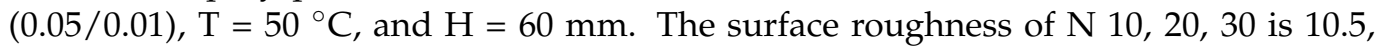
14.5 , and $24.1 \mathrm{~nm}$, respectively, and the thickness is $129.7,224.9$, and $337.2 \mathrm{~nm}$, respectively. Their Ra increases with the increase in the number of spray passes. There is a linear relationship between the thickness and the number of spray passes. Therefore, we can control the film thickness by controlling the number of spray passes. Based on the above results, the solution concentration of $\mathrm{SiO}_{2} / \mathrm{PVP}(0.05 / 0.01)$, substrate temperature of $50{ }^{\circ} \mathrm{C}$, and nozzle-to-substrate distance of $60 \mathrm{~mm}$ were employed in the following spray coating studies.

Figure 6a shows an even cross-sectional SEM image of a $\mathrm{SiO}_{2} / \mathrm{PVP}$ film when the spray pass is 30 and the film thickness is measured to be $337 \mathrm{~nm}$. The surface SEM image of the film presented certain small pits. Just as shown in Figure $6 \mathrm{~b}$, spraying defects become apparent as the number of spray passes increases. Then, a high magnification SEM image of $\mathrm{SiO}_{2}$ shows particle morphology as depicted in Figure $6 \mathrm{c}$ and PVP fills the spaces between the particles. Energy dispersive X-ray (EDX) mappings and the spectrum of $\mathrm{C}, \mathrm{O}$, and $\mathrm{Si}$ elements derived from SEM images (Figure 6d) demonstrate that all these elements are distributed throughout the surface uniformly.
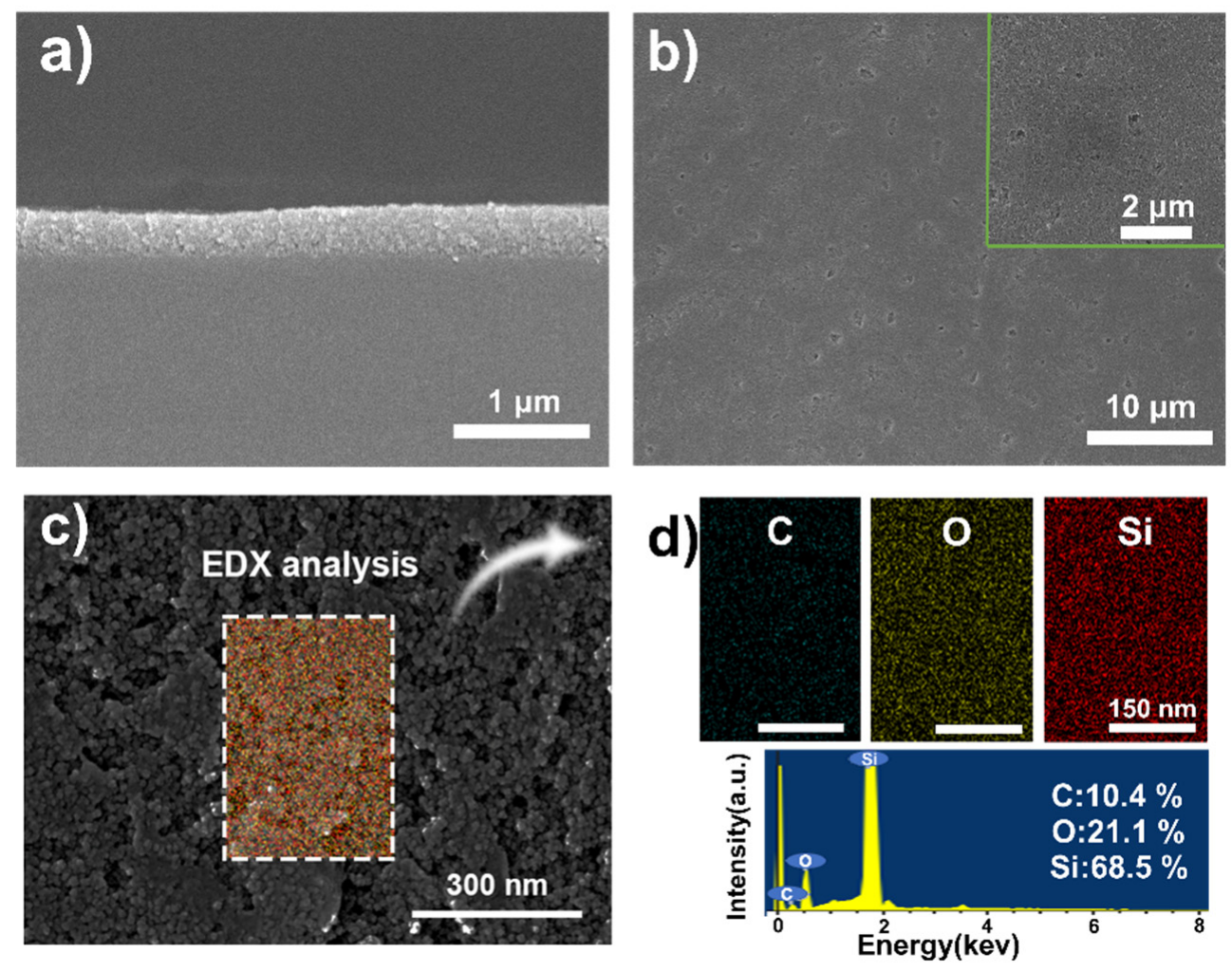

Figure 6. (a) Cross-sectional SEM image, (b) surface SEM image, (c) SEM image of high magnification, and (d) elemental (C, O, and $\mathrm{Si}$ ) mappings and EDX spectrum of the nanofilm with spray passes of 30 .

\subsection{Optical Properties of Structure Color Films}

During the assembly process of the film, we controlled the thickness by changing the number of spray passes, preparing different structural color films. In addition, it 
was measured that the refractive index of the $\mathrm{SiO}_{2} / \mathrm{PVP}$ layer was 1.38. The theoretical refractive indices of air and silicon are 1 and 3.8, respectively [39]. In this case, the condition for constructive interference is $2 n d \cos \theta=m \lambda$, where $d$ is the thickness of the $\mathrm{SiO}_{2} / \mathrm{PVP}$ film, $\theta$ is the angle of the incident wave, $\lambda$ is the wavelength of interference light, $n$ is the refractive index, and $m$ is an integer [40]. Figure 7a shows that when $\mathrm{N}$ is 20,22, 24, 26,28 , and 30, the thickness of the film is $225.6,248.3,270.1,295.4,313.4$, and $337.2 \mathrm{~nm}$, respectively, as shown in Table S2, and the reflection wavelength is 424.7, 471.5, 525.4, 549.4 , and $602.3 \mathrm{~nm}$, respectively. Their digital photographs present purple, blue, green, yellow-green, brown, purplish red, respectively. The reflectance spectrum changes of a $\mathrm{SiO}_{2} / \mathrm{PVP}$ film $(\mathrm{N}=26)$ by varying the incident angles are shown in Figure $7 \mathrm{~b}$. When the observing angles are $5^{\circ}, 25^{\circ}, 35^{\circ}, 45^{\circ}$, and $75^{\circ}$, their digital photographs present green, blue, light blue, light red, and red, respectively. This shows that as the incident angle continues to increase, the position of the reflection peak gradually blue-shifts. These are both in good accordance with the thin-film interference law. With the previously optimized conditions, we carried out the spraying experiment on round silicon wafers with diameters of $15 \mathrm{~cm}$, and prepared three pieces of $\mathrm{SiO}_{2}$ film with green, red, and blue colors, as displayed in Figure 7c.
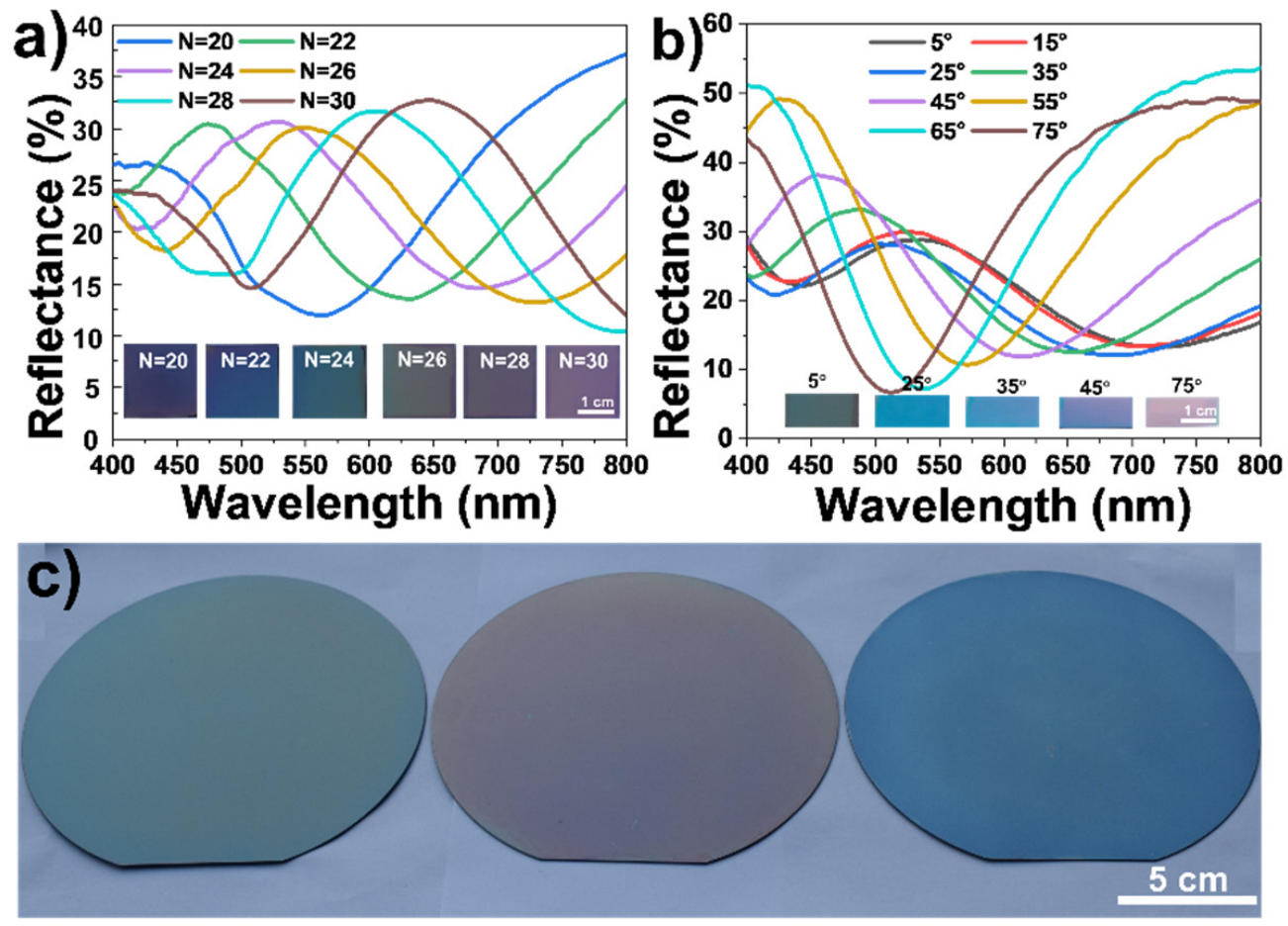

Figure 7. (a) Digital photographs and reflectance spectra. (b) Reflectance spectra of structural color film with spray passes of 26 at different incident angles. (c) Photographs of structural color films at an incident angle of $15^{\circ}$.

\subsection{Hydrophilic Property and Humidity Responsiveness of the Nanofilms}

In addition to coloration and large-area preparation, we also found that the films had strong hydrophilicity. The dynamic change in water contact angle and the surface morphology of the films with different spray passes were studied and the results are shown in Figure 8. As shown in Figure 8a, after $1.6 \mathrm{~s}$, the water contact angle of the 10-pass film decreased from the initial $25^{\circ}$ to $11.5^{\circ}$ and reached a stable level. The AFM image in Figure 8d shows that the film has a uniform surface; Figure 8b presents that the water contact angle of the film with $\mathrm{N}=20$ decreases from $23^{\circ}$ to $9^{\circ}$ and its surface morphology becomes uneven and rough as displayed in Figure 8e. Figure 8c shows that the water contact angle of the film with $\mathrm{N}$ of 30 is only $8^{\circ}$ and the AFM image presents an even rougher surface and small holes as displayed in Figure $8 \mathrm{f}$. The above results demonstrate 
that as the thickness of the film increases, both surface roughness and hydrophilicity increase. These unique surface wetting properties are attributed to the water adsorption properties of mesoporous structures and the hydrophilic $\mathrm{SiO}_{2} / \mathrm{PVP}$ composite, which benefit the diffusion and penetration of water within the film.
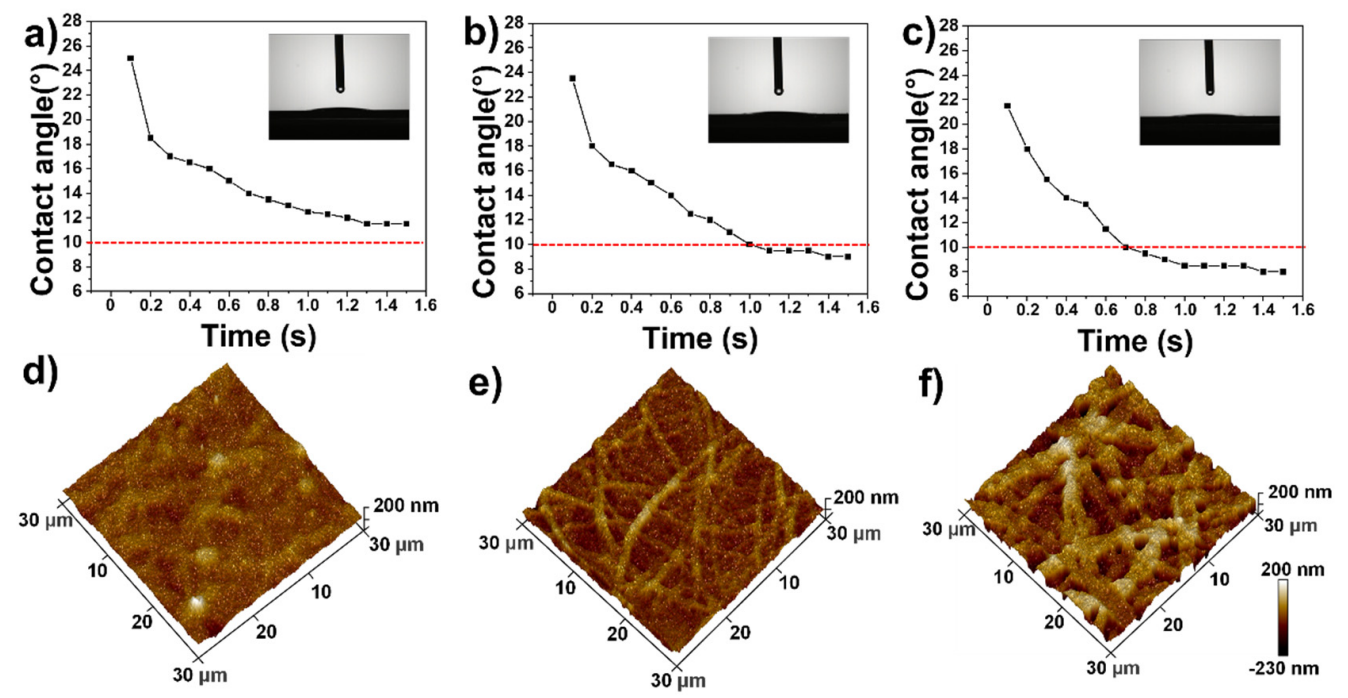

Figure 8. Water contact angles of structural color film with spray passes of (a) $N=10,(\mathbf{b}) \mathrm{N}=20$, and (c) $\mathrm{N}=30$ at different times; 3D AFM images of structural color film with spray passes of (d) $\mathrm{N}=10$, (e) $\mathrm{N}=20$, and (f) $\mathrm{N}=30$.

We found that the film had a very sensitive color change response to environmental humidity as shown in Figure 9. The sensing properties for various relative humidity were monitored by comparing the structure colors and recording the reflectance spectra. Figure $9 \mathrm{a}$ shows that with the relative humidity ( $\mathrm{RH}$ ) increased from $33 \%$ to $45 \%, 75 \%, 86 \%$, and $97 \%$, the color of the film quickly turned from violet to green, orange, light pink, pink and blue, respectively, realizing humidity response discoloration. In Figure $9 a$, the reflected wavelength varied from 487.6 to $541.1,581.6,639.6$, and $678.2 \mathrm{~nm}$. An obvious bathochromic shift was observed when the film was stimulated by water molecules. The mechanism for color change by varying humidity is based on the change in refractive index of the film, which results from the adsorption and penetration of water vapor within the thin coating. Based on the coloration mechanism of thin-film interference, as Equation $2 n d \cos \theta=m \lambda$ shows, the reflection wavelength $\lambda$ of the film is proportional to the refractive index $n$. When water molecules penetrate into the film, its refractive index increases as the air within the film is replaced by the water vapor, resulting in a color change and red-shift of the reflection wavelength. Due to the color change of the intelligent film upon exposure to different $\mathrm{RH}$, we realize naked-eye recognition of humidity change.

In addition, the response and recovery time of the humidity sensor were tested based on human blowing. The process is shown in Video S3 and Figure S6 in the Supplementary Information. As can be seen from the video, upon exposure to the blowing, the color of the sample immediately changed, from blue-green to light yellow, and then to pink red, which took $0.9 \mathrm{~s}$. After stopping blowing, the color quickly changed back to blue-green; the recovery time was about $0.6 \mathrm{~s}$. Therefore, the total time was only $1.5 \mathrm{~s}$, demonstrating a very sensitive humidity response. The color variation mainly resulted from the change in reflective index of the film after adsorption and desorption of water, and the very fast response and recovery are attributed to the mesoporous structure of the hydrophilic nanofilm, which facilitates rapid absorption and release of the water molecules. Figure S7 shows ten cyclic response tests of the structural color film at $\mathrm{RH}$ of $33 \%$ and $97 \%$. The positions of the reflection peaks change reversibly from about $480 \mathrm{~nm}$ to $680 \mathrm{~nm}$, indicating good cyclic stability of the film for humidity response. 

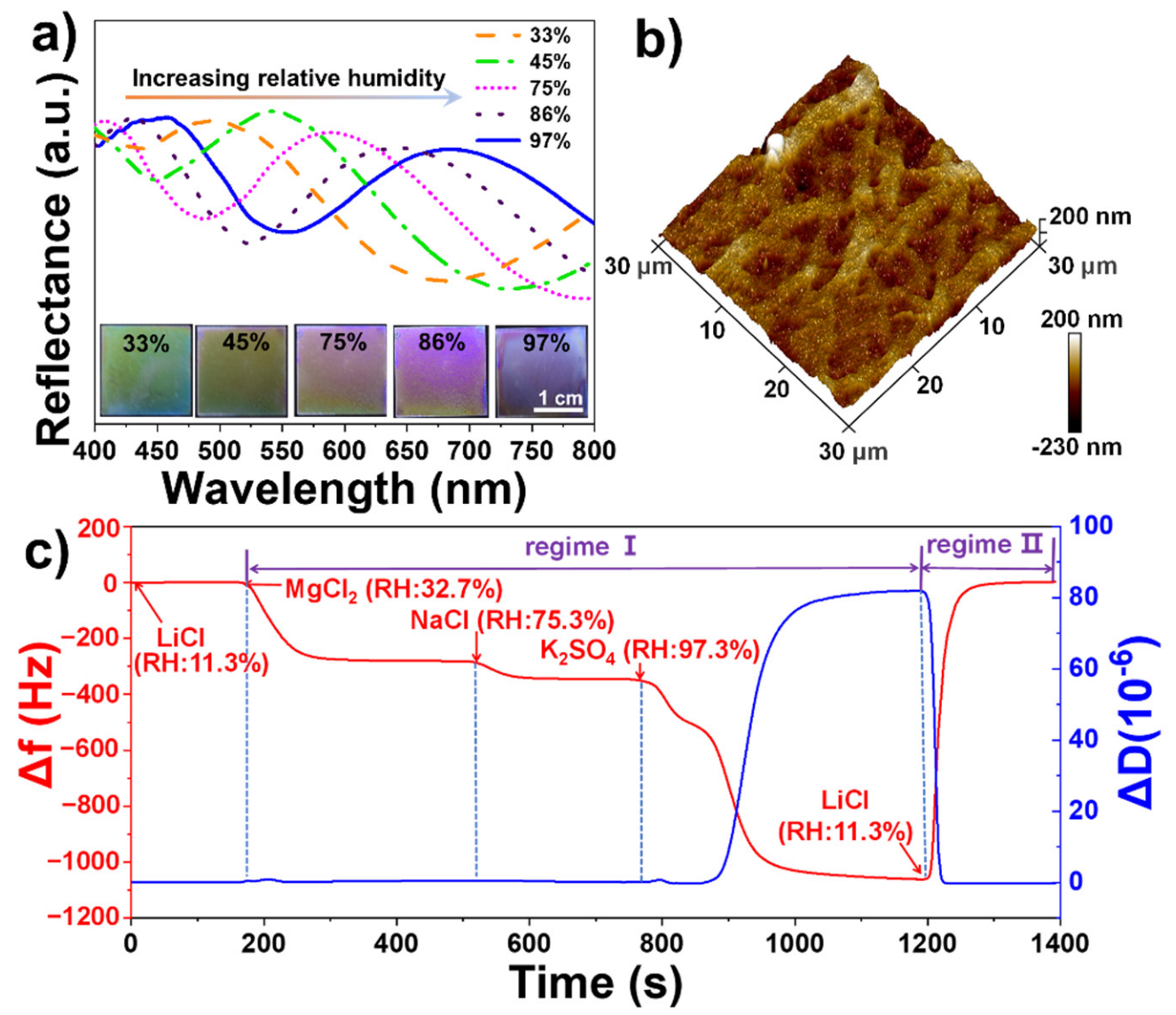

Figure 9. (a) Reflectance spectra of the structural color film with spray passes of $\mathrm{N}=26$ upon exposure to different relative humidity, (b) its 3D AFM image, and (c) variations in frequency and dissipation on a gold-coated chip when exposed to different relative humidity.

To better understand the sensing and adsorbing dynamics, quartz crystal microbalance with dissipation (QCM-D) monitoring was implemented for in situ measurements of mass changes in the range of nanograms as a frequency shift $(\Delta \mathrm{f})$ and of viscoelastic changes as a dissipation shift $(\Delta \mathrm{D})$. For example, $\Delta \mathrm{f}$ is expected to decrease when $\mathrm{SiO}_{2}$ films attached to the QCM-D sensor adsorb water vapor, and the value of $\Delta \mathrm{D}$ will rise if a viscoelastic property of the attaching layer increases, which can directly demonstrate the adsorption and condensation of water vapor on the surface of the film. Variations in $\Delta \mathrm{f}$ and $\Delta \mathrm{D}$ of the $\mathrm{SiO}_{2}$ film assembled on a gold-coated chip when exposed to different relative humidity are displayed in Figure 9c.

As visualized in Figure $9 \mathrm{c}$, we used saturated $\mathrm{LiCl}, \mathrm{MgCl}_{2}, \mathrm{NaCl}$, and $\mathrm{K}_{2} \mathrm{SO}_{4}$ solution to create $11.3 \%, 32.7 \%, 75.3 \%$, and $97.3 \%$ humidity environments at $25{ }^{\circ} \mathrm{C}$, respectively [41]. At the initial stage (Regime I), $\mathrm{LiCl}$ solution was injected to produce an $11.3 \%$ water vapor environment; $\Delta \mathrm{f}$ and $\Delta \mathrm{D}$ reached balances rapidly, which were set as the reference baselines $(\Delta \mathrm{f}=0 ; \Delta \mathrm{D}=0)$. Then $\mathrm{MgCl}_{2}$ saturated solution was injected into the chamber to produce a $32.7 \%$ water vapor environment; the $\Delta \mathrm{f}$ decreased obviously and immediately owing to the increased mass of the film that stemmed from the strong water absorption capacity of the $\mathrm{SiO}_{2}$ films with an uneven surface in the 3D AFM images in Figure 9b. As less water vapor enters the pores on the surface of the $\mathrm{SiO}_{2}$ film, $\Delta \mathrm{D}$ of the film does not change. The time to reach adsorption equilibrium is $29 \mathrm{~s}$. Subsequently, $\mathrm{NaCl}$ saturated solution was introduced into the testing system to produce a $75.3 \%$ water vapor environment and the data curves of $\Delta \mathrm{f}$ further decreased and $\Delta \mathrm{D}$ has no significant change in values. We can see that the water vapor adsorption mass of the film decreases and reaches equilibrium in a shorter time. Next, $\mathrm{K}_{2} \mathrm{SO}_{4}$ saturated solution was introduced into the testing system to produce a $97.3 \%$ water vapor environment. The $\Delta \mathrm{f}$ experienced a two-step gradient 
descent. It first decreased to $-527 \mathrm{~Hz}$ within $80 \mathrm{~s}$, then quickly decreased to $-1032 \mathrm{~Hz}$; for $\Delta \mathrm{D}$, in the first $80 \mathrm{~s}$, when $\mathrm{RH}$ changed to $97.3 \%$, it still kept unchanged, and then it directly increased to $83 \times 10^{-6}$. The distinct changes in both $\Delta \mathrm{f}$ and $\Delta \mathrm{D}$ are presumably owing to water vapor condensation in the film. The vapor was first adsorbed on the surface, then entered the holes; when the RH was high enough, water vapor began to condense, resulting in a viscoelasticity increase. When the saturated $\mathrm{LiCl}$ solution was again passed through to create a humidity of $11.3 \%$ (Regime II), the film was restored to the initial stage, which proves that the adsorption of water vapor on the film is fully reversible.

For comparison, the humidity response of spin coating films with the same thickness was prepared and a QCM-D humidity test was conducted. As shown in Figure S8, the adsorption capacity of water vapor on the spin-coated $\mathrm{SiO}_{2} / \mathrm{PVP}$ film is much weaker than that of the sprayed one when the $\mathrm{RH}$ changes from $11.3 \%$ to $97.3 \%$, and the $\Delta \mathrm{f}$ change is only $120 \mathrm{~Hz}$, which is much less than the $1051 \mathrm{~Hz}$ change of the sprayed film. The reason for this is that the surface of the $\mathrm{SiO}_{2}$ film prepared by spin coating is dense, which is not conducive to the adsorption of water vapor.

\section{Conclusions}

In summary, structural colors show potential applications in colorimetric sensing, display, and coating; however, due to the difficulty in large-area manufacturing of the smart colors, their application is limited. In this study, a recently developed technique (ultrasonic spraying-coating) was employed and large-area ultra-thin structural color films were successfully constructed. For the first time, the drying process of ultra-sonic spray droplets was tracked by an optical microscope, and it was confirmed that PVP as an auxiliary can inhibit coffee rings and reduce roughness. Meanwhile, the experiments confirm the optimal process parameters: the concentration of $\mathrm{SiO}_{2} / \mathrm{PVP}$ is $0.05 \mathrm{wt} \% / 0.01 \mathrm{wt} \%$, the optimal substrate temperature is $50^{\circ} \mathrm{C}$, and the optimum nozzle distance is $60 \mathrm{~mm}$. By controlling the number of spray passes, we prepared uniform structural color films with $15 \mathrm{~cm}$ diameters. The nanofilms are intelligent and show quick color changes in response to humidity variations, which is attributed to their mesoporous and hydrophilic structures. QCM-D results prove that the composite film has a stronger ability to adsorb water vapor compared with that prepared with the spin-coating method. In summary, ultrasonic spraycoating technology provides promising application prospects for large-area production of functional structural color films.

Supplementary Materials: The following are available online at https://www.mdpi.com/article/ 10.3390/polym13213768/s1, Figure S1: Viscosity of the spray solutions at different temperatures; Figure S2: Film surface profile of spraying at (a) $\mathrm{SiO}_{2} / \mathrm{PVP}(0.05 / 0.01)$, (b) $\mathrm{SiO}_{2} / \mathrm{PVP}(0.10 / 0.02)$, (c) $\mathrm{SiO}_{2} / \mathrm{PVP}(0.15 / 0.03)$, and (d) $\mathrm{SiO}_{2} / \mathrm{PVP}(0.20 / 0.04)$ at $\mathrm{T}=50^{\circ} \mathrm{C}$; Figure S3: Film surface profile at (a) $\mathrm{T}=40^{\circ} \mathrm{C}$, (b) $50{ }^{\circ} \mathrm{C}$, and (c) $60^{\circ} \mathrm{C}$ at $\mathrm{SiO}_{2} / \mathrm{PVP}(0.05 / 0.01)$ and $\mathrm{H}=60 \mathrm{~mm}$; Figure S4: Film surface profile at (a) $\mathrm{H}=70$, (b) $\mathrm{H}=65$, (c) $\mathrm{H}=60$, and (d) $\mathrm{H}=55 \mathrm{~mm}$, at $\mathrm{SiO}_{2} / \mathrm{PVP}(0.05 / 0.01$ ) and $\mathrm{T}=50^{\circ} \mathrm{C}$; Figure S5: Film surface profile of spray passes at (a) $\mathrm{N}=10$, (b) $\mathrm{N}=20$, and (c) $\mathrm{N}=30$, at $\mathrm{SiO}_{2} / \mathrm{PVP}(0.05 / 0.01), \mathrm{T}=50^{\circ} \mathrm{C}$ and $\mathrm{H}=60 \mathrm{~mm}$; Figure S6: The response and recovery time of humidity sensing; Figure S7: Recycle detection test of the structure color film in $33 \%$ and $97 \%$ relative humidity environment; Figure S8: Variations of frequency and dissipation by spin-coating $\mathrm{SiO}_{2} / \mathrm{PVP}$ on a gold-coated chip when exposed to different relative humidity conditions. Table S1: Surface tension of the solutions; Table S2: Structure color film thickness; Video S1: Droplet drying process of $\mathrm{SiO}_{2}(0.05)$; Video S2: Droplet drying process of $\mathrm{SiO}_{2} / \mathrm{PVP}(0.05 / 0.01)$; Video S3: The response and recovery time of humidity sensing.

Author Contributions: Conceptualization, W.M. and S.L.; methodology, W.M.; software, S.L.; validation, S.L., W.M. and D.K.; formal analysis, S.L.; investigation, S.L.; resources, W.M.; data curation, S.L.; writing—original draft preparation, S.L.; writing—-review and editing, S.L.; visualization, D.K.; supervision, W.M.; project administration, S.Z.; funding acquisition, W.M. All authors have read and agreed to the published version of the manuscript.

Funding: This research was financially supported by the National Natural Science Foundation of China (21878040, 21978041), the Fundamental Research Funds for the Central Universities (DUT19TD28), the 
Natural Science Foundation of Liaoning Province (2019-MS-037), and the Liaoning Revitalization Talent Program (CLXC1801006).

Institutional Review Board Statement: Not applicable.

Informed Consent Statement: Not applicable.

Data Availability Statement: All the data are available within the manuscript.

Conflicts of Interest: The authors declare no conflict of interest.

\section{References}

1. Ito, M.M.; Gibbons, A.H.; Qin, D.; Yamamoto, D.; Jiang, H.; Yamaguchi, D.; Tanaka, K.; Sivaniah, E. Structural colour using organized microfibrillation in glassy polymer films. Nature 2019, 570, 363-367. [CrossRef]

2. Dumanli, A.G.; Savin, T. Recent advances in the biomimicry of structural colours. Soc. Rev. 2016, 45, 6698-6724. [CrossRef] [PubMed]

3. Yu, X.L.; Ma, W.; Zhang, S.F. Hydrophobic polymer-incorporated hybrid 1D photonic crystals with brilliant structural colors via aqueous-based layer-by-layer dip-coating. Dye. Pigment. 2020, 186, 108961. [CrossRef]

4. Daqiqeh Rezaei, S.; Dong, Z.G.; You En Chan, J.; Trisno, J.; Ng RJ, H.; Ruan, Q.; Qiu, C.-W.; Mortensen, N.A.; Yang, J.K.W. Nanophotonic Structural Colors. ACS Photonics 2020, 8, 18-33. [CrossRef]

5. Fenzl, C.; Hirsch, T.; Wolfbeis, O.S. Photonic crystals for chemical sensing and biosensing. Angew. Chem. Int. Ed. 2014, 53, 3318-3335. [CrossRef]

6. Kinoshita, S.; Yoshioka, S.; Miyazaki, J. Physics of structural colors. Rep. Prog. Phy. 2008, 71, 076401-076431. [CrossRef]

7. Meng, F.T.; Umair, M.M.; Zhang, S.F.; Jin, X.; Tang, B.T. Thermal-guided interfacial confinement to fabricate flexible structural color composites for durable applications. J. Mater. Chem. C 2019, 7, 11258-11264. [CrossRef]

8. Fu, Y.L.; Tippets, C.A.; Donev, E.U.; Lopez, R. Structural colors: From natural to artificial systems. Wiley Interdiscip. Rev. Nanomed. Nanobiotechnol. 2016, 8, 758-775. [CrossRef]

9. Moon, C.W.; Park, J.E.; Park, M.; Kim, Y.; Narasimha, K.; Hyun, J.K.; Park, S.J. Responsive Thin-Film Interference Colors from Polaronic Conjugated Block Copolymers. ACS Appl. Mater. Interfaces 2021, 13, 1555-1561. [CrossRef]

10. Hong, S.H.; Song, J.K. Comment on “Tunable Design of Structural Colors Produced by Pseudo-1D Photonic Crystals of Graphene Oxide" and Thin-Film Interference from Dried Graphene Oxide Film. Small 2017, 13, 1603125. [CrossRef] [PubMed]

11. Mathger, L.M.; Hanlon, R.T. Malleable skin coloration in cephalopods: Selective reflectance, transmission and absorbance of light by chromatophores and iridophores. Cell Tissue Res. 2007, 329, 179-186. [CrossRef] [PubMed]

12. Kramer, R.M.; Crookes-Goodson, W.J.; Naik, R.R. The self-organizing properties of squid reflectin protein. Nat. Mater. 2007, 6, 533-538. [CrossRef] [PubMed]

13. Phan, L.; Walkup, W.G.T.; Ordinario, D.D.; Karshalev, E.; Jocson, J.M.; Burke, A.M.; Gorodetsky, A.A. Reconfigurable infrared camouflage coatings from a cephalopod protein. Sci. Rep. 2017, 7, 44927-44934. [CrossRef] [PubMed]

14. Gerislioglu, B.; Dong, L.L.; Ahmadivand, A.; Hu, H.T.; Nordlander, P.; Halas, N.J. Monolithic Metal Dimer-on-Film Structure: New Plasmonic Properties Introduced by the Underlying Metal. Nano Lett. 2020, 20, 2087-2093. [CrossRef] [PubMed]

15. Yadav, A.; Gerislioglu, B.; Ahmadivand, A.; Kaushik, A.; Cheng, G.J.; Ouyang, Z.; Wang, Q.; Yadav, V.S.; Mishra, Y.K.; Wu, Y.; et al. Controlled self-assembly of plasmon-based photonic nanocrystals for high performance photonic technologies. Nano Today 2021, 37, 101072. [CrossRef]

16. Seo, H.B.; Lee, S.Y. Bio-inspired colorimetric film based on hygroscopic coloration of longhorn beetles (Tmesisternus isabellae). Adv. Mater. 2013, 25, 5621-5625. [CrossRef]

17. Richardson, J.J.; Bjornmalm, M.; Caruso, F. Multilayer assembly. Technology-driven layer-by-layer assembly of nanofilms. Science 2015, 348, aaa2491. [CrossRef]

18. Kou, D.H.; Zhang, S.F.; Lutkenhaus, J.L.; Wang, L.; Tang, B.T.; Ma, W. Porous organic/inorganic hybrid one-dimensional photonic crystals for rapid visual detection of organic solvents. J. Mater. Chem. C 2018, 6, 2704-2711. [CrossRef]

19. Han, H.G.; Weerasinghe, H.C.; Min Kim, K.; Soo Kim, J.; Cheng, Y.B.; Jones, D.J.; Holmes, A.B.; Kwon, T.H. Ultrafast Fabrication of Flexible Dye-Sensitized Solar Cells by Ultrasonic Spray-Coating Technology. Sci. Rep. 2015, 5, 14645. [CrossRef] [PubMed]

20. Liu, H.S.; Chang, W.C.; Chou, C.Y.; Pan, B.C.; Chou, Y.S.; Liou, G.S.; Liu, C.L. Controllable Electrochromic Polyamide Film and Device Produced by Facile Ultrasonic Spray-coating. Sci. Rep. 2017, 7, 11982. [CrossRef]

21. Routledge, T.J.; Lidzey, D.G.; Buckley, A.R. Ultrasonic spray coating as an approach for large-area polymer OLEDs: The influence of thin film processing and surface roughness on electrical performance. AIP Adv. 2019, 9, 15330. [CrossRef]

22. Williams, B.A.; Trejo, N.D.; Wu, A.; Holgate, C.S.; Francis, L.F.; Aydil, E.S. Copper-Zinc-Tin-Sulfide Thin Films via Annealing of Ultrasonic Spray Deposited Nanocrystal Coatings. ACS Appl. Mater. Interfaces 2017, 9, 18865-18871. [CrossRef]

23. Chou, L.H.; Wang, X.F.; Osaka, I.; Wu, C.G.; Liu, C.L. Scalable Ultrasonic Spray-Processing Technique for Manufacturing Large-Area CH3NH3PbI3 Perovskite Solar Cells. ACS Appl. Mater. Interfaces 2018, 10, 38042-38050. [CrossRef]

24. Millington, B.; Whipple, V.; Pollet, B.G. A novel method for preparing proton exchange membrane fuel cell electrodes by the ultrasonic-spray technique. J. Power Sources 2011, 196, 8500-8508. [CrossRef] 
25. McGrath, M.G.; Vrdoljak, A.; O'Mahony, C.; Oliveira, J.C.; Moore, A.C.; Crean, A.M. Determination of parameters for successful spray coating of silicon microneedle arrays. J. Int. J. Pharm. 2011, 415, 140-149. [CrossRef]

26. Han, W.; Lin, Z.Q. Learning from "coffee rings": Ordered structures enabled by controlled evaporative self-assembly. Angezw. Chem. Int. Ed. 2012, 51, 1534-1546. [CrossRef]

27. Sopoušek, J.; Humlíček, J.; Hlaváček, A.; Horáčková, V.; Skládal, P.; Lacina, K. Thick nanoporous matrices of polystyrene nanoparticles and their potential for electrochemical biosensing. Electrochim. Acta 2021, 368, 137607. [CrossRef]

28. Yunker, P.J.; Still, T.; Lohr, M.A.; Yodh, A.G. Suppression of the coffee-ring effect by shape-dependent capillary interactions. Nature 2011, 476, 308-311. [CrossRef]

29. Poulichet, V.; Morel, M.; Rudiuk, S.; Baigl, D. Liquid-liquid coffee-ring effect. Colloid Interface Sci. 2020, 573, 370-375. [CrossRef]

30. Sauleda, M.L.; Chu, H.C.W.; Tilton, R.D.; Garoff, S. Surfactant Driven Marangoni Spreading in the Presence of Predeposited Insoluble Surfactant Monolayers. Langmuir 2021, 37, 3309-3320. [CrossRef]

31. Cui, L.Y.; Zhang, J.H.; Zhang, X.; Huang, L.; Wang, Z.H.; Li, Y.F.; Gao, H.N.; Zhu, S.J.; Wang, T.Q.; Yang, B. Suppression of the coffee ring effect by hydrosoluble polymer additives. ACS Appl. Mater. Interfaces 2012, 4, 2775-2780. [CrossRef] [PubMed]

32. Still, T.; Yunker, P.J.; Yodh, A.G. Surfactant-induced Marangoni eddies alter the coffee-rings of evaporating colloidal drops. Langmuir 2012, 28, 4984-4988. [CrossRef]

33. Chen, M.; Sala, G.; van Valenberg, H.J.F.; van Hooijdonk, A.C.M.; van der Linden, E.; Meinders, M.B.J. Foam and thin films of hydrophilic silica particles modified by beta-casein. J. Colloid Interface Sci. 2018, 513, 357-366. [CrossRef] [PubMed]

34. Liu, Y.Y.; Cai, Z.X.; Sheng, L.; Ma, M.H.; Xu, Q. Influence of nanosilica on inner structure and performance of chitosan based films. Carbohydr. Polym. 2019, 212, 421-429. [CrossRef] [PubMed]

35. Jiang, J.; Shen, Y.; Yu, D.H.; Yang, T.; Wu, M.H.; Yang, L.; Petru, M. Porous Film Coating Enabled by Polyvinyl Pyrrolidone (PVP) for Enhanced Air Permeability of Fabrics: The Effect of PVP Molecule Weight and Dosage. Polymers 2020, 12, 2961. [CrossRef]

36. Bhardwaj, R.; Fang, X.; Somasundaran, P.; Attinger, D. Self-assembly of colloidal particles from evaporating droplets: Role of DLVO interactions and proposition of a phase diagram. Langmuir 2010, 26, 7833-7842. [CrossRef] [PubMed]

37. Li, C.Y.; Dai, W.B.; Duan, F.; Zhang, Y.M.; He, D. Fatigue Life Estimation of Medium-Carbon Steel with Different Surface Roughness. Appl. Sci. 2017, 7, 338. [CrossRef]

38. Bose, S.; Keller, S.S.; Alstrom, T.S.; Boisen, A.; Almdal, K. Process optimization of ultrasonic spray coating of polymer films. Langmuir 2013, 29, 6911-6919. [CrossRef]

39. Qin, M.; Sun, M.; Bai, R.; Mao, Y.Q.; Qian, X.S.; Sikka, D.; Zhao, Y.; Qi, H.J.; Suo, Z.; He, X.M. Bioinspired Hydrogel Interferometer for Adaptive Coloration and Chemical Sensing. Adv. Mater. 2018, 30, e1800468. [CrossRef]

40. Kinoshita, S.; Yoshioka, S. Structural colors in nature: The role of regularity and irregularity in the structure. ChemPhysChem 2005, 6, 1442-1459. [CrossRef]

41. Hong, T.D.; Edgington, S.; Ellis, R.H.; de Muro, M.A.; Moore, D. Saturated salt solutions for humidity control and the survival of dry powder and oil formulations of Beauveria bassiana conidia. J. Invertebr. Pathol. 2005, 89, 136-143. [CrossRef] [PubMed] 